\title{
CHRONIC LYMPHOBLASTIC LEUKEMIA DIAGNOSED BY PRIMARY CUTANEOUS LESION
}

\author{
AMIN DANANDEH MEHR ${ }^{1}$, YOUSEF ROOSTA ${ }^{2}$, ZAHRA MASHHADI ${ }^{3 *}$ \\ ${ }^{1}$ Department of Hematology and Oncology, Ardabil University of Medical Sciences, Ardebil, Iran. ${ }^{2}$ Department of Internal Medicine, \\ Urmia University of Medical Sciences, Urmia, Iran. ${ }^{3}$ Faculty of Medicine, Ardebil University of Medical Sciences, Ardabil, Iran. \\ Email: zh.mashhadi98@gmail.com
}

Received: 12 February 2021, Revised and Accepted: 24 March 2021

\section{ABSTRACT}

Chronic lymphocytic leukemia (CLL) is a malignant, low-grade, monoclonal disorder characterized by the accumulation of lymphocytes with variable clinical features. Cutaneous manifestations or leukemia cutis are non-specific, uncommon presentations of CLL and can present in many different ways. In this case report, we discuss a 76-year-old male who presented with skin lesions of the lower limbs and severe itching. Due to the lack of response to the treatment with topical corticosteroids, initial tests were carried out. Complete blood count results indicated lymphocytosis. Eventually Ultimately, the skin lesions led to the diagnosis of CLL. The patient was treated with bendamustine-rituximab (BR). After receiving the treatment, all cutaneous manifestations and generalized itching disappeared. This case highlights the importance of comparing similar cases of CLL presented with dermatological conditions in order to to understand proper management and practice.

Keywords: Chronic lymphocytic leukemia, Skin lesions, Lymphocytic vasculitis, Leukemia cutis.

(C) 2021 The Authors. Published by Innovare Academic Sciences Pvt Ltd. This is an open access article under the CC BY license (http://creativecommons, org/licenses/by/4.0/) DOI: http://dx.doi.org/10.22159/ijms.2021v9i3.41102. Journal homepage: https://innovareacademics.in/journals/index.php/ijms

\section{INTRODUCTION}

Chronic lymphocytic leukemia (CLL) which is the most common form of leukemia is a low-grade lymphoproliferative disorder. Clinical presentations of CLL can be a variable spectrum of features [1] Although CLL usually presents with classic manifestations, in some cases, it appears with unusual or rare externalizations [2]. Cutaneous manifestations and skin lesions which are called leukemia cutis are rare presentations of CLL and occur in $4-25 \%$ of patients and usually do not appear as the first sign of the disease [3]. In this case, we report a patient with CLL who has presented with a flat skin lesion, erythema, and severe itching.

\section{CASE REPORT}

A 76-year-old man with a medical history of hypertension and no prior chemotherapy presented with flat lesions of the lower limbs and severe itching (Fig. 1). The patient was examined by a dermatologist 2 months before the admission and treated with topical corticosteroids and antihistamines. As a consequence of the lack of response to the treatment initial tests were conducted.

Complete blood count test revealed WBC $18.67\left({ }^{*} 109 \mathrm{~L}\right)$, RBC $3.21\left({ }^{*} 10\right.$ $12 \mathrm{~L})$, hemoglobin $9.8(\mathrm{~g} / \mathrm{dl})$, HCT $31.5 \%$, and PLT $198\left({ }^{*} 109 \mathrm{~L}\right)$. Blood differential test showed lymphocyte $90.8 \%$, neutrophil $8.6 \%$, monocyte $0.4 \%$, eosinophil $0.2 \%$, and basophil $0.0 \%$. Due to the lymphocytosis as the result of conducted tests, the patient was referred to a hematologist for further examinations.

Computed tomography scan indicated a few small lymph nodes on the base of the neck, significant adenopathy in the posterior triangle of the neck, adenopathy in the axillary regions, and mild splenomegaly with the length of $156 \mathrm{~mm}$ (Fig. 2).

To conduct a further examination, the biopsy of itching cutaneous lesions was carried out. Microscopical findings showed skin tissue with moderate perivascular lymphocytic aggregation and vessel damage. In conclusion, pathological studies of lesions indicated lymphocytic vasculitis.
Results of peripheral blood flow cytometry showed the percentage of reactivities of the cells with the MoAbs. CD20 was $71 \%$ as a B-cell marker, CD5 was $93 \%$ as a T-cell marker, CD23 was 77\%, and CD 10 was reported negative.

Bone marrow aspiration and biopsy revealed an obvious increase in lymphoid proliferation (Fig. 3).

As the result of conducted tests and examinations, diagnosis of CLL was confirmed. According to the Rai staging system for CLL, our patient had Stage III CLL.

After confirmation of the diagnosis of CLL, the patient was treated with bendamustine-rituximab. The administered dose of rituximab was $700 \mathrm{mg}$ on the $1^{\text {st }}$ day. On the $2^{\text {nd }}$ and $3^{\text {rd }}$ day, the administered dose of bendamustine was $150 \mathrm{mg}$.

The patient tolerated chemotherapy and 1 day after the first period of prescribed chemotherapy, the symptoms were improved and itching was resolved (Fig. 4).

The patient consent for using the information and images has been taken.

\section{DISCUSSION}

CLL is considered as the most common adult leukemia worldwide and among all leukemia in the United States, CLL accounts for $25-30 \%$ of cases [4].

Cutaneous eruptions and dermatological conditions in CLL have been identified in $4-25 \%$ of patients $[3,5]$. Cutaneous manifestations of CLL may be presented primarily as leukemia cutis or more commonly as secondary lesions [6].

Typical presentations ofleukemia cutis in CLLare erythematous papules, plaques, nodules, or large tumors. According to the histopathological findings, cutaneous infiltrations in CLL can be described with three architectural patterns. These patterns are patchy perivascular and periadnexal, band-like, and nodular diffuse [7]. 


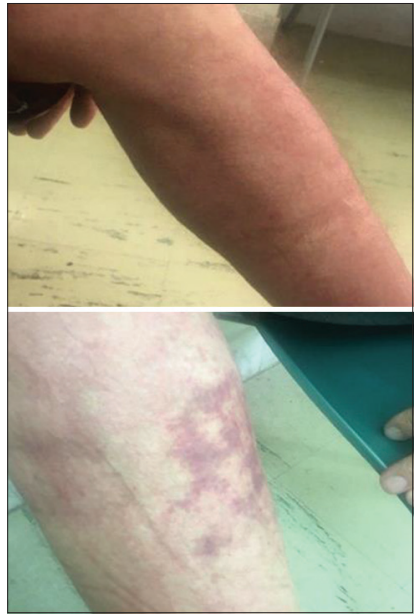

Fig. 1: Skin lesions of the lower limbs like flat lesions without papules or pustules

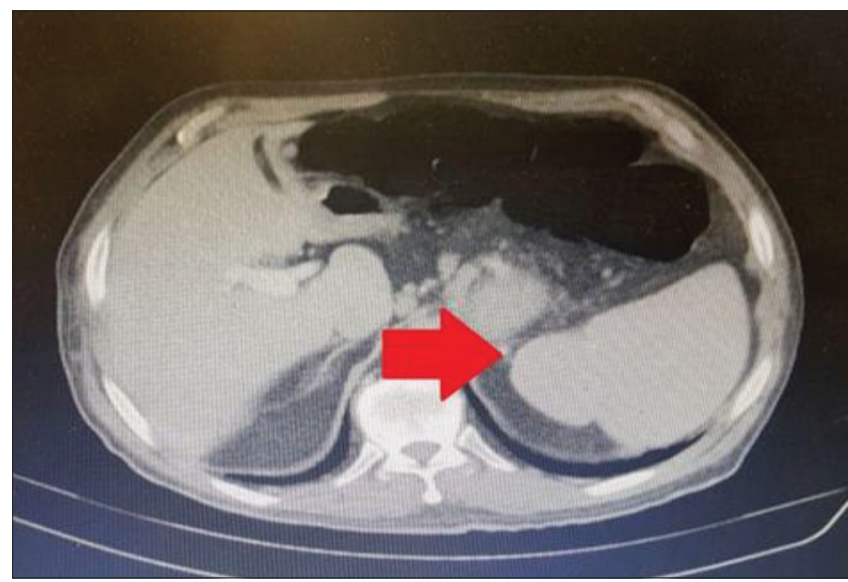

Fig. 2: Mild splenomegaly revealed by computed tomography scan

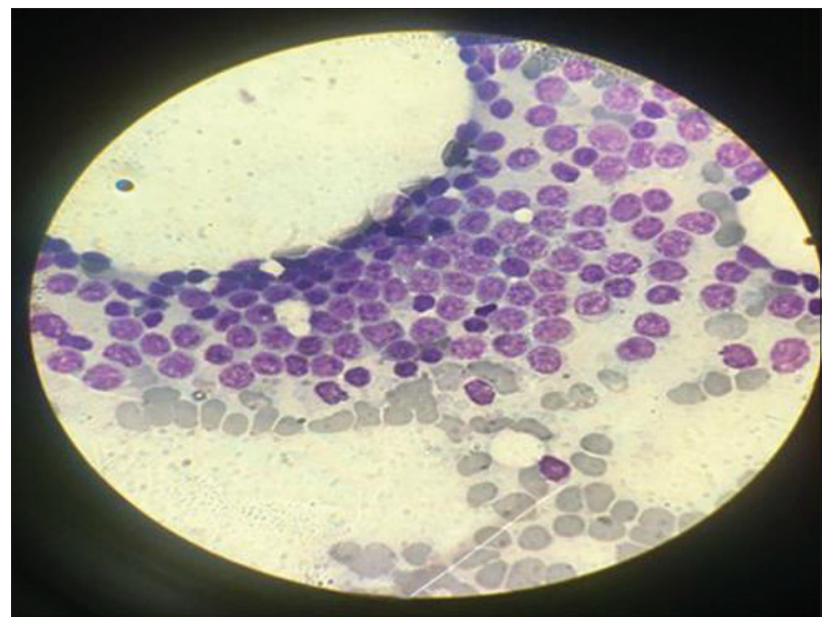

Fig. 3: Bone marrow aspiration reveals increase in lymphoid proliferation $[\times 1000]$

Although previous case reports suggested the notion that leukemia cutis leads to a negative prognosis, recent data and studies indicate that in the absence of progressed systemic disease, cutaneous involvement in CLL does not affect prognosis [8].

Similar cases of CLL with cutaneous manifestations has have been documented and reported. Lu et al. reported a patient with subclinical

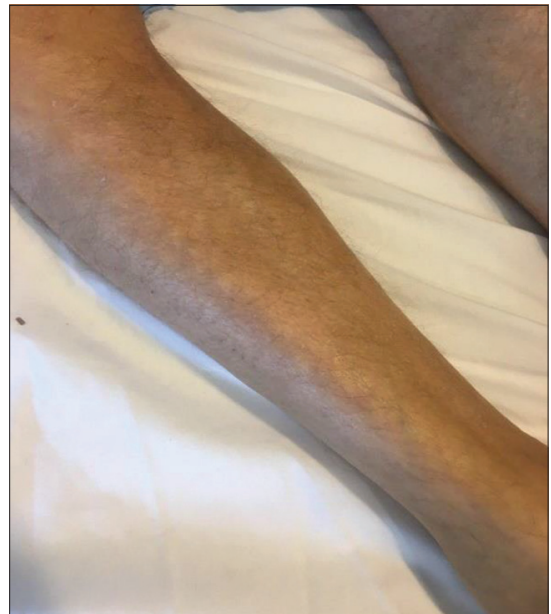

Fig. 4: The conditions of skin lesions in the same areas after the first course of chemotherapy

B-cell CLL presented with skin hypertrophic changes of the ears, eyebrows, tip of the nose, toes, and fingers. According to this case report, considering leukemia cutis in patients with underlying CLL is important [9].

Another case reported by Raufi et al. who introduced a patient with the skin lesion of bilateral ears. This cutaneous manifestation led to the diagnosis of CLL [10].

This case, by describing a flat skin lesion with erythema and severe itching of the lower limb as an unusual clinical manifestation of CLL, highlights the importance of considering leukemia cutis as a harbinger of underlying CLL (Fig. 1).

Although our case suggests that early cutaneous manifestations of CLL can lead to the diagnosis. Further investigations and comparison of similar cases is are needed to enhance our understanding of disease as well as proper management and practice.

\section{CONCLUSION}

Cutaneous lesions which do not answer to the common treatments should be considered serious and to diagnose the main disorder and rule out the differential diagnosis further examinations should be ruled out.

\section{ACKNOWLEDGMENTS}

In preparation of our case report, we had to take the help of our colleagues in Imam Khomeini hospital, who deserve our deepest gratitude.

\section{REFERENCES}

1. Chiorazzi N, Chen SS, Rai KR. Chronic lymphocytic leukemia. Cold Spring Harb Perspect Med 2021;11:a035220.

2. Mikaelsson E. Towards New Therapeutic Targets: Identification of Novel Tumor Markers in Chronic Lymphocytic Leukemia. Solna, Sweden: Karolinska University; 2010.

3. Słomiak-Wasik A, Jałowska M, Iwanik K, Żaba R, Adamski Z. Erythrodermic psoriasis de novo versus skin lesions in chronic lymphocytic leukaemia. Adv Dermatol Allergol 2020;37:277-9.

4. Siegel RL, Miller KD, Jemal A. Cancer statistics, 2016. CA Cancer J Clin 2016;66:7-30.

5. Siegel RS, Gartenhaus RB, Kuzel TM. Human T-cell lymphotropic-Iassociated leukemia/lymphoma. Curr Treat Options Oncol 2001;2:291-300.

6. Ziemer M, Bornkessel A, Hahnfeld S, Weyers W. 'Specific' cutaneous infiltrate of B-cell chronic lymphocytic leukemia at the site of a florid herpes simplex infection. J Cutan Pathol 2005;32:581-4.

7. Cerroni L, Zenahlik P, Höfler G, Kaddu S, Smolle J, Kerl H. Specific 
cutaneous infiltrates of B-cell chronic lymphocytic leukemia: A clinicopathologic and prognostic study of 42 patients. Am J Surg Pathol 1996;20:1000-10

8. Aldapt MB, Yassin MA. Leukemia cutis as an early presentation or relapsing manifestation of Chronic Lymphocytic Leukemia (CLL): Leukemia cutis in chronic lymphocytic leukemia. Acta Biomed 2021;92:e2021192.
9. Lu C, Li L, Qiao Q, Liu G, Fang L. Cutaneous manifestations in a patient with chronic lymphocytic leukemia involving the head, neck and distal extremities. Exp Ther Med 2015;9:877-9.

10. Raufi A, Alsharedi M, Khelfa Y, Griswold DC, Lebowicz Y Leukemia cutis in a patient with chronic lymphocytic leukemia presenting as bilateral helical nodules. SAGE Open Med Case Rep 2016;4:2050313X16683624. 